\title{
LETTER
}

\section{Avoidable statistical pitfalls in analyzing length of stay in intensive care units or hospitals}

\author{
Martin Wolkewitz \\ See related research by Shahin et al., http://ccforum.com/content/17/5/R251
}

In a study of ventilated patients in a recent issue of Critical Care, Shahin and colleagues [1] compared the length of stay in ICU between patients who acquired a suspected ventilator-associated respiratory infection (sVARI) and patients who remained free of this infection. There are two basic facts that require special attention in the statistical analysis. First, ventilation is a timedependent study entry since some patients receive ventilation a few days after the time of admission to the ICU. In keeping with the study design, these patients cannot be discharged between admission and first ventilation; ignoring this fact leads to length bias [2]. Second, sVARI is a time-dependent exposure since sVARI might occur a few days after the start of ventilation; treating sVARI incorrectly as time-fixed (that is, assumed to be known at the time of admission) leads to time-dependent bias [2]. The statistical models used by Shahin and colleagues incorrectly assumed that ventilation and sVARI occurrence already happened at the day of admission. Both types of bias can be substantial in such settings: in a study of patients colonized with methicillin-resistant Staphylococcus aureus (MRSA), the biased extra length of hospital stay of MRSA-infected patients was 24.5 days whereas the correct estimate was only 6 days [2]. Length and time-dependent bias are avoidable types of bias since the chronological order (admission, time of first ventilation, time of sVARI, and time of discharge) can be acknowledged in a multi-state model [2]. Researchers are encouraged to use adequate models to receive valid results for hospital-acquired infections [3].

\section{Authors' response \\ Jason Shahin and Arnold S Kristof}

We thank Dr Wolkewitz for indicating the effects of length and time-dependent biases in studies that use survival analyses to infer a causal link between a timedependent exposure and time-based clinical outcomes. The time-dependent bias in the study attempting to establish $S$. aureus bacteremia as a cause of increased duration of admission is a good example, especially since the exposure tends to occur later in the ICU course. In our study on sVARIs [1], we looked for an association between sVARI and patient co-morbidities or outcomes common to contemporary ICUs. Although we focused on iatrogenic immunosuppression, there was also an association between sVARI and duration of mechanical ventilation or length of stay. However, we did not wish to imply a causal effect of sVARI on the latter outcomes. As Wolkewitz indicates, this would require a prospective proportional hazards-based analysis accounting for the duration of admission or mechanical ventilation prior to sVARI in a multi-state model. In contrast, our findings also incorporate a potential effect of duration of mechanical ventilation or ICU stay on the prevalence of sVARI and in part describe the nature of the patient who develops sVARI. This observation would likely be lost in a multi-state model. Nonetheless, we agree with Dr Wolkewitz that it would be of interest to incorporate the time to event in a separate statistical analysis that attempts to address a potential causal effect between sVARI and time-dependent clinical outcomes.

\footnotetext{
Correspondence: wolke@imbi.uni-freiburg.de

Center for Medical Biometry and Medical Informatics, Institute for Medical Biometry and Statistics, Medical Center - University of Freiburg, Stefan-Meier-Str. 26, 79104 Freiburg, Germany
} 


\section{Abbreviations}

MRSA: Methicillin-resistant Staphylococcus aureus; sVARI: Suspected ventilatorassociated respiratory infection.

\section{Competing interests}

The author declares that he has no competing interests.

\section{Published: 19 Feb 2014}

\section{References}

1. Shahin J, Bielinski M, Guichon C, Flemming C, Kristof AS: Suspected ventilatorassociated respiratory infection in severely ill patients: a prospective observational study. Crit Care 2013, 17:R251.

2. Wolkewitz $M$, Allignol $A$, Harbarth $S$, de Angelis $G$, Schumacher M, Beyersmann J: Time-dependent study entries and exposures in cohort studies can easily be sources of different and avoidable types of bias. J Clin Epidemiol 2012, 65:1171-1180

3. Schumacher M, Allignol A, Beyersmann J, Binder N, Wolkewitz M: Hospitalacquired infections - appropriate statistical treatment is urgently needed! Int J Epidemiol 2013, 42:1502-1508.

$10.1186 / \mathrm{cc} 13735$

Cite this article as: Wolkewitz: Avoidable statistical pitfalls in analyzing

length of stay in intensive care units or hospitals. Critical Care 2014, 18:408 